\title{
Surgimiento y evolución de las escenas Rock, Punk y Metal en Tailandia
}

\author{
InCEPTION ANd EVOlution of Rock, Punk \\ and Metal scenes in Thailand
}

\section{Pablo Henri Ramírez Didou ${ }^{1}$}

Resumen: Este artículo en un primer lugar explora la aparición y evolución del rock en Tailandia como subcultura musical de la juventud tailandesa desde los años 80 hasta la fecha. Se verá cómo a partir del surgimiento de una escena de rock metal, el underground musical en Bangkok se diversificó en una multitud de géneros musicales como el Punk, el Hardcore o el rock independiente. La segunda parte toma en cuenta tres factores que son cruciales para explicar el proceso de sensibilización e ingreso a la subcultura del rock en Bangkok: la exposición a los medios de comunicación, la introducción musical vía los amigos o la familia, y los contactos hechos durante los estudios universitarios.

Palabras clave: juventud, rock, Tailandia.

Abstract: The article explores the inception and evolution of rock music in Thailand as a musical subculture for the Thai youth from the 1980s to this date. It will present how from the creation of a Metal scene, underground rock music in Bangkok diversified itself in a myriad of music genres such as Punk, Hardcore or Indie Rock. The second part of this article will explore three factors that are of high importance in

\footnotetext{
${ }^{1}$ Estudió en el Centro sobre estudios tailandeses, Universidad de Chulalongkorn, Bangkok, Tailandia. El artículo es producto de su tesis de doctorado titulada "Emergencia de un Rock'n'roll auténtico e identidad juvenil tailandesa; un reflejo de la subcultura de la clase media en el Bangkok contemporáneo”.

Correo electrónico: pabloramdi@gmail.com

Fecha de recepción: 2509 15; Fecha de aceptación: 011215.
}

(cc) EY-NC-ND Páginas 131-158. 
the sensitization process leading to entering the rock'n'roll subculture in Bangkok: The influence of the media, being introduced to the music by peers and family, and Universities as a platform to create a network of contacts with fellow musicians.

Keywords: Youth, Rock, Thailand.

La historia de la música rock underground en Tailandia es rica desde la década de los 80 a la actualidad. Las primeras bandas que emergieron después de la explosión comercial del puea chiwit — música folk tradicional, liderada por Carabao ${ }^{2}$ — fueron de Trash Metal: Dezember, Macaroni y Surrender of Divinity, mismas que transformaron la música comercial tailandesa con sonidos y estilos extremadamente distorsionados, lo que reveló las demandas siempre cambiantes en Bangkok por maneras alternativas de vida y por géneros musicales acordes con éstas.

Las bandas de Heavy Metal abrieron camino a grupos que propusieron una música más ruidosa, misma que fue incorporada al circuito tailandés de música pirata, mediante casetes, y contribuyó a difundir un nuevo tipo de música que tomaba en cuenta las experiencias de la gente que vivía en Bangkok. Este artículo explora la historia y la evolución del rock underground en esta ciudad, desde que surgió a finales de los 80 hasta la fecha, y analiza quiénes participan de esa subcultura musical y cómo se inician en ella.

La investigación que se presenta es una reconstrucción histórica basada en entrevistas personales con 23 miembros importantes y activos en la subcultura del rock en Bangkok, así como mediante charlas con otros miembros de las diferentes escenas musicales. Los entrevistados fueron seleccionados al cumplir con la siguiente lista de criterios: llevan más de 5 años como miembros activos en la escena musical local; han presentado uno o más $\mathrm{CD}$ con sus respectivos proyectos musicales

\footnotetext{
${ }^{2}$ Carabao es una banda que mezcló canciones tradicionales con música rock; obtuvo éxito internacional a finales de los 80 y principios de los 90 con su canción "Made in Thailand".
} 
de manera independiente; y son dueños o trabajan directamente en pequeñas empresas que se dedican a la promoción y desarrollo del rock underground en Bangkok. Las entrevistas fueron llevadas a cabo en inglés y tailandés durante el año 2014.

\section{El surgimiento del rock underground tailandés}

Un nuevo contexto en la sociedad se dio por los cambios surgidos en los valores sociales y musicales de los años 80. Una clase media emergente creó una infraestructura propia para diseminar sus gustos y su ideología. Espectáculos de rock en vivo empezaron a darse en clubes como el Rock Pub o el Immortal Bar, donde se presentaron conciertos utilizando equipos técnicos y musicales de mejor calidad que los que habían utilizado en su tiempo los grupos de puea chiwit, ofreciendo presentaciones en campus universitarios y pueblos con básicos instrumentos acústicos. Como escribió Kasian Tejapira en su ensayo "The Postmodernization of Thainess" (2001: 153): “Thainess becomes unanchored, uprooted, liberated or freed from the regime of reference to national or ethnic Thai commodities with the liberation of national identity as signifier from the control of specific national or ethnic commodity referents". En otras palabras, muchos jóvenes hoy conocen poco de la música tradicional tailandesa, pero conocen mucho sobre las estructuras de las canciones de rock y su estética, que se ha vuelto ahora global y local, dado que las perciben como algo directamente relacionado con ellos. Sin embargo, aunque adoptados por una minoría, estas formas y sonidos no están siempre aceptados por el colectivo social dominante debido a su novedad y su alejamiento de los valores convencionales.

Basándonos en las teorías de Thomson (1966) y Frykman y Lofgren (1987), quienes exponen que las clases sociales crean cultura, es más fácil analizar a la clase media tailandesa. En efecto, si nos enfocamos a la sociedad tailandesa, al tener dinero, educación y acceso a las últimas tecnologías, la clase media ha logrado crear su propio estilo de vida de una manera muy específica e imposible de emular por parte de otras clases: diseminando su ideología a través de los medios de comunicación. Según Ockey (2004), es la clase media la que se encarga de escribir 
y editar periodicos y revistas, la que crea campañas publicitarias, la que crea y programa la televisión y radio, y la que enseña a su propia juventud en las universidades. Al tener este control académico y mediático, la clase media tailandesa se construye a sí misma de manera "académica, ideológica y cultural" (Ockey, 2004: 153) y logra crear una cultura dominante que impone al resto de la sociedad.

Es en este caso que es de singular interés estudiar la subcultura del rock en Tailandia. Al ser parte de un movimiento cultural desarrollado en su mayoría por jóvenes universitarios, la música rock en Tailandia permite a una pequeña parte de la clase media el expresarse libremente y oponerse a la cultura dominante impuesta por los medios de comunicación. Es necesario estudiar estas tribus musicales porque se desarrollan en el seno de uno de los bastiones ideológicos de la clase media tailandesa: sus universidades. Ahí donde las futuras élites son formadas es donde gran parte de los jóvenes que acaban por involucrarse en la música rock aprenden a tocar, forman bandas y se rebelan contra la ideología de su propia clase. Para poder entender esto, es también necesario examinar los orígenes y las fuentes de la cultura popular así como lo que lleva a los jóvenes a involucrarse en este tipo de música y en la subcultura que ésta conlleva.

Lo anterior nos ayuda a develar los conflictos dialécticos internos en la sociedad tailandesa, en particular con una generación de jóvenes que no siempre se siente escuchada. Como lo mostramos más adelante, muchos músicos de rock'n'roll provienen de la clase media y fueron influenciados por los grupos de Heavy Metal, populares a finales de los 80, y por las primeras bandas de rock Indie —independiente-, que aparecieron a principios de los 90. Pese a ser musicalmente distintos, ambos géneros de rock'n'roll estuvieron articulados con los procesos identitarios de los jóvenes tailandeses que se reconocieron en ellos. Los principales grupos locales que salieron al escenario público en Bangkok encontraron a su vez su inspiración inicial en la escucha durante años de los casetes piratas de grupos extranjeros.

La estabilidad política y la prosperidad económica durante los 90 llevaron a lo que Apanich (2002) calificó como una era de "canciones para la música”. Nuevas bandas difundieron nuevos sonidos, con una 
promoción comercial mínima y preocupaciones introspectivas alejadas de los compromisos políticos. A mediados de los 90, surgieron las primeras bandas independientes, por ejemplo Modern Dog and Krub, cuya actuación, durante una primera etapa, anunciaba lo que vendría después. Introdujeron los términos "indie” —independiente_ y "underground" en el escenario musical tailandés, y propusieron estilos y expresiones distintas a los acostumbrados (Apanich, 2002), e incluso diferentes a los del género pop lukkrung. ${ }^{3}$

En el 2000, el ethos musical del rock underground devino completamente en DiY — Do-it-yourself_- los artistas crearon su propia música, escribieron sus propias letras, produjeron y promocionaron su obra y, recurriendo a las nuevas tecnologías como Internet, la comercializaron en medios sociales como MySpace, Facebook o YouTube. La música de rock Metal nació como una reacción al pop que invadía incesantemente los medios de comunicación. Sin embargo, el Metal era una respuesta vacía comparado al movimiento anti-bélico y prodemocracia surgido en los años 60. El Metal era más bien una respuesta ruidosa y estética a la música pop y sus estereotipos. Aunque se diluyó a principios de los 90, la semilla había sido plantada entre una nueva generación de músicos y compositores, cada uno eligiendo su propio camino, según la evolución social y del desarrollo del contexto (Apanich, 2002). El rock Metal implicaba técnica y timing. Se requería que las bandas tocaran cada vez más rápido mientras utilizaban armonías complicadas y solos instrumentales infinitos en canciones de duración creciente. Sin embargo, las nuevas generaciones querían oír nuevas expresiones musicales que correspondieran a las emociones y opiniones que suscitaban sus contextos. El rock independiente les proporcionó esa oportunidad.

Los distintos estilos y géneros musicales en Bangkok abarcan un espectro variado de actitudes culturales y perspectivas. Las nuevas generaciones de músicos están refiriéndose a influencias musicales más

${ }^{3}$ Lukkrung, literalmente "hijo de la ciudad", es un género musical similar a la música pop que se expandió en medios urbanos. Sus temas giran en torno al amor y a las relaciones conflictivas. El lukkrung, asociado con audiencias de clases medias y altas, se diferencia así de lukthung, principalmente popular entre la gente de la región norteña de Isaan. 
heterogéneas que sus antecesores, lo que explica por qué, hoy en día, la escena musical moderna es tan variada en sus sonidos y ofertas. La idea de que la música debe ser "cruda" y no refinada, pero con corazón y ciertas actitudes, dio paso a bandas emergentes con nuevas letras. El arte de la creación musical se consolidó e incluyó incluso a apasionados con limitadas habilidades musicales. El hecho de que los costos de los equipos musicales y la tecnología se abarataron produjo que darse a conocer deviniera más fácil, gracias a la utilización de los nuevos medios de comunicación y la Internet. Experimentar con sonidos innovadores se hizo posible mediante viajes al extranjero y surfeando en Internet. La actitud del Do-it-Yourself ha proliferado en la juventud tailandesa. Confiados en que hacían una música genuina, los partidarios de la estética DiY consolidaron sus capacidades organizacionales al margen de las infraestructuras dominantes establecidas por los medios de comunicación de masas. Organizaron espectáculos, publicaron gacetas y periódicos, crearon marcas disqueras e incluso tuvieron sus emisiones de radio. El siguiente apartado estará en consecuencia dedicado a analizar como el rock'n'roll y los múltiples escenarios donde se produce se fueron desarrollando a partir de los 80 .

\section{Metal}

Las bandas de Trash Metal lideraron la subcultura de la música rock que surgió en Bangkok después del movimiento del pleng puea chiwit durante la segunda parte de los 80 . Se caracterizaron por un sonido profundamente distorsionado, con letras difícilmente comprensibles y largos y estridentes solos de guitarra. Su música era muy distinta de los estilos tradicionales de música popular tailandesa y pop difundidos por los medios.

La primera ola de las bandas de Metal, que utilizaban guitarras, bajos y baterías, inició espectáculos que eran más ruidosos, agresivos y acelerados que los que habían sido producidos antes en Bangkok. Manejó una moda e imaginario dark que aludían directamente al dolor y la muerte, mediante la utilización de representaciones gráficas en los diseños de portada de sus discos y la vestimenta de los músicos

\footnotetext{
${ }^{4}$ Versión tailandesa de la música folk.
} 
y de sus fans. La juventud tailandesa se reveló hambrienta de este tipo de música, misma que colmó sus necesidades musicales mediante los casetes piratas y el mercado de $\mathrm{CD}$ que estaba en rápida expansión a finales de los 80 en Bangkok. Igual que la música, cambió la moda. El estilo puea chiwit suponía vestir vaqueros y camisetas. Los metaleros promovieron una vestimenta más extravagante, con el pelo largo, botas con puntas de acero y chaquetas de cuero. Vestirse fue considerado como un pronunciamiento contra la sociedad de masas y una manera de identificarse con semejantes. En palabras de Myers-Moro, "no sólo las palabras pero también las texturas, los instrumentos, los contextos de los conciertos, son rasgos que cobran significado mediante las experiencias sociales" (1986: 93). La moda no fue solamente parte de la experiencia sub-cultural cotidiana sino que permitió demostrar por qué el movimiento puea chiwit había dejado de ser llamativo para las poblaciones que convocó en un principio, una vez que fue diluido en una aceptación social basada en su mercantilización por los medios masivos de comunicación. En ese contexto, el Metal y sus representaciones actuaron como un revulsivo en la subcultura del rock'n'roll y propusieron un nuevo comienzo a la juventud tailandesa que estaba en busca de su propia identidad moderna.

Era la época en la que el desarrollo de Bangkok era incesante. La moneda nacional, el baht, estaba firmemente amarrado al dólar estadounidense, los créditos y las transacciones monetarias se realizaban con tasas jamás vistas antes. Esos fenómenos llevaron a una modernización de las infraestructuras urbanas, un desarrollo sostenido de los negocios y la expansión de condominios y plazas comerciales que formarían la línea de los rascacielos de Bangkok. El Producto Nacional Bruto aumentó muy rápidamente. Durante casi dos décadas, la economía creció $7.8 \%$ anual, mientras el ingreso per cápita se elevaba de 2,100 baht en 1961 a 68,000 en 1995. Esa etapa de crecimiento explicó la consolidación de la clase media y, junto con ello, la creación de un mercado de consumo de masas. Esta nueva infraestructura económica y mediática saturó el mercado musical local con sus productos y artistas, dejando de lado a la juventud en busca de nuevas fuentes de expresión cultural. Las bandas de Heavy Metal prepararon el camino a 
una música más fuerte y distorsionada orientada al ruido, y encontró canales de distribución en el mercado de los productos piratas, muy en boga en ese momento. Los casetes no sólo " hicieron la música accesible a los tailandeses en una forma totalmente nueva y reflejaron claramente cambios en los valores musicales y sociales" (Wong, 1995: 43), sino que también generaron nuevas experiencias comprensivas de la música entre los habitantes de Bangkok.

Estos cambios socioculturales en la clase media fueron difundidos por la juventud que creó nuevas infraestructuras de producción, reproducción y distribución que diseminaron sus gustos e ideología, principalmente el hecho de que se querían disociar de los medios masivos y del estatus quo. Para los jóvenes, la música era una manera de expresar al mismo tiempo sus ideas sobre modernidad, política y vida cotidiana en Bangkok. Las historias de la vida pueblerina o los problemas de amor eran insignificantes para ellos y estaban desconectados de sus experiencias existenciales diarias. Les interesaba más oír sobre los problemas cotidianos de vivir en el caos de una ciudad como Bangkok, del tráfico interminable, la basura en las calles, de la corrupción de políticos y de la policía o simplemente sobre la vida universitaria y las dificultades de abrirse un camino en la vida profesional.

Los espectáculos en vivo de rock'n'roll se volvieron más comunes y empezaron a abrirse clubes dedicados a esa subcultura. Lugares tales como Rock Pub, Metal Zone, y el Immortal Bar, se volvieron populares y atrajeron cada vez más público local a sus eventos. Estos lugares instalaron sistemas costosos de sonido, con grandes amplificadores, micrófonos y luces. Los músicos de Metal tenían guitarras elaboradas a propósito y muchos utilizaban efectos con pedales que eran caros de comprar. En comparación, los músicos de puea chiwit eran pobres en recursos acústicos. La subcultura del Metal, incluida en la subcultura del rock'n'roll, representó una forma de alejarse de la música tradicional tailandesa, pero el contexto histórico en el que emergió le dio credibilidad y le aseguró una afiliación con la cultura tailandesa. El Metal se volvió relevante para la clase media porque era asociado a la par al ser moderno y al ser tailandés a finales de los 80 , permitiendo a los jóvenes demarcarse de sus padres sin romper con su linaje. 
Hoy, muchas bandas conocen más de la historia del rock local que acerca de la música clásica tradicional tailandesa. Aunque son conscientes de la naturaleza global del rock'n'roll, re-interpretan sus contenidos y letras vinculándolos a su situación particular. No obstante el rock no ha sido adoptado masivamente por la sociedad tailandesa debido a su novedad y a su distancia en relación con los cánones sociales imperantes; lo que sigue es una breve historia de esta subcultura y de los espacios donde se desplegó a partir de los 90.

\section{La consolidación de la subcultura del rock'n'roll}

Como señalamos anteriormente, la primera ola de Trash Metal derivó de una reacción de la juventud de clase media contra la música pop, masivamente difundida por los medios de comunicación. Esto creó un nuevo entorno que permitió aglutinar una comunidad deseosa de pensar y vivir fuera de los límites impuestos por los medios de comunicación de masas.

Conforme se produjo la absorción gradual del Metal por la cultura hegemónica y sus medios de comunicación, mediante campañas de marketing y la realización de eventos musicales donde participaron bandas como Lam Morrison y Hi-Rock, el Heavy Metal y su cultura se volvieron parte de la cultura de masas. Una vez más, canciones edulcoradas y power ballads empezaron a llenar las ondas radiofónicas, y el escenario musical que había sido un choque cultural en Bangkok se estancó, perdiendo relevancia.

El Metal fue víctima de su éxito comercial. Sin embargo, muchos jóvenes urbanos tailandeses no se desanimaron y continuaron la búsqueda de estilos musicales distintos. La juventud suele buscar su propia identidad mientras llega a la edad adulta. En el caso tailandés, la música constituyó un referente significativo para quienes la consideraron como un soporte para realizarse y relacionarse con los demás. Habiendo crecido en una mezcla que capitalizó el pop y la cultura dominante, la clase media tailandesa utilizó la infraestructura existente para instalar distintos escenarios para el rock'n'roll, expresando así sus aspiraciones culturales y conflictos dialécticos. Esa recién creada cultura del rock'n'roll le proporcionó un circuito aparte de las instituciones 
tradicionales y de los valores familiares en el que podían experimentar y crear su propio estilo e identidad. Gracias al espíritu del Do-It-Yourself los jóvenes tailandeses tuvieron la oportunidad de crear y distribuir su propia música sin tener que pasar por las infraestructuras de aprobación y censura del gobierno. Al desarrollarse de manera underground, el rock en Bangkok reflejaba el estilo e identidad de aquellos jóvenes que no aceptaban lo que los medios de comunicación describían como la imagen perfecta del tailandés de clase media: alguien joven, dedicado a su familia, al budismo y a la nación, que desarrolla su carrera con el único fin de acumular dinero para poder estar siempre a la moda e invertir en nuevos negocios y desarrollar el negocio familiar.

Los monopolios en la industria cultural llevaron a privilegiar expresiones culturales no-provocativas y comercializables, sustitutivas o complementarias a las formulas del pop instaladas y perfeccionadas durante los 80 y los 90. Marginalizaron a los músicos que no querían plegarse a esos procedimientos impuestos por las industrias culturales. Gary Boyle, periodista y cineasta independiente, me explicó que una vez que un grupo independiente había firmado un contrato con una disquera comercial, se sumía en un proceso en el que la disquera definía el tipo de público al que podían gustar y les enviaba durante unos dos años a tocar en plazas comerciales y eventos patrocinados por la propia disquera. Si uno quería tener éxito comercial como músico, debía de atenerse a ese esquema: la industria musical en Tailandia estaba bien organizada para "lavar el cerebro de productores, artistas y músicos, para que crean que ser bonitos y no originales eran las únicas vías para ser exitosos"(Gary Boyle, entrevista, 1ero de junio de 2014). Sin embargo, ese bloqueo a expresiones musicales creativas no detuvo a los jóvenes de clase media interesados en la subcultura del rock'n'roll, sino que los orilló a adoptar el modelo del Do-it-Yourself (DiY) en la comunidad musical.

DiY es un término acunado en los 70 en Gran Bretańa por el movimiento Punk. En ese entonces, el movimiento Punk era abiertamente anti-establishment y glorificaba el individualismo y el nihilismo. Aborrecía la cultura-basura del Pop, el consumismo y empujaba a sus adherentes a crear sus propios bienes y cultura. En 
Tailandia, el referente de la cultura basura es el Pop. Hay una lista infinita de éxitos que atiborraron los medios de comunicación con canciones intrascendentes y superficiales. No obstante, en 1994, la música contemporánea en Bangkok y Tailandia conoció una revolución que emergió de las cenizas del Metal, la del rock Indie o independiente (Apanich, 2002). Impulsado por bandas como Krub y Modern Dog, ese género musical exploró nuevos sonidos y efectos visuales, que tuvieron gran impacto en la audiencia.

"Descubrimos que podíamos hacer algo diferente, ellos — Krub and Modern Dog_ influyeron tanto en muchos de nosotros que parecía que todos mis amigos de la Universidad estuvieran tocando en una banda", señaló Pok, de la banda Stylish Nonsense (Wannarit 'Pok' Pongprayoon, entrevista 2 de marzo de 2014).

Foto 1: Wannarit 'Pok' Pongprayoon, tocando con Plastic Section en Harmonica.

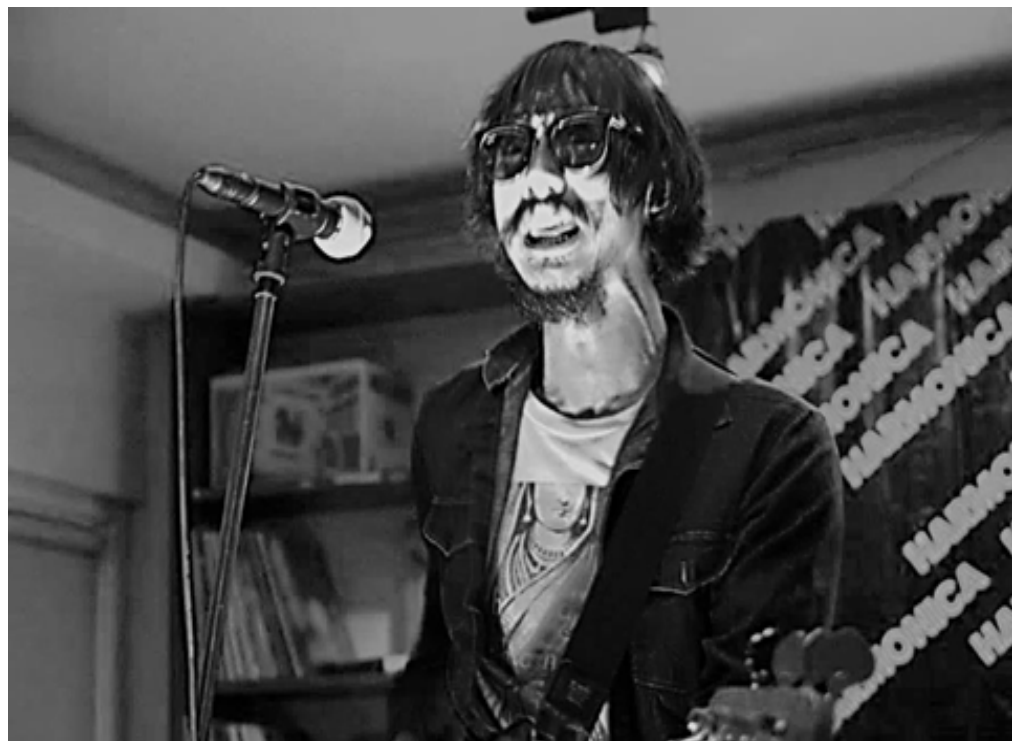

Krub y Modern Dog propusieron un nuevo sonido a sus escuchas, dejaron atrás las distorsiones y las técnicas de juego rápido del Metal y 
ensayaron un sonido más influenciado por las bandas de Britpop — genero de rock-pop inglés surgido en el principio de los 90-. El darse cuenta de que uno es capaz de "hacer algo diferente" por sí mismo es el punto focal del DiY. El Punk y su mentalidad individualizada de hacer las cosas por mano propia ingresó a Tailandia vía la cultura del DiY. Nuevas bandas fueron creadas y, con ellas, nuevas disqueras independientes que las representaron.

La música del Metal en los 80 giraba en torno a la rapidez del tempo y a la técnica en progresiones intrincadas de acordes, mientras se gritaban liricas rápidas en el micrófono. El rock independiente estaba más interesado en explorar nuevas expresiones musicales vinculadas con las emociones y opiniones que generaba el entorno. Músicalmente hablando, "las nuevas generaciones estaban hartas y aburridas con el Metal. La primera oleada de músicos independientes de los 90 se inspiró mucho del Britpop. La segunda oleada, la de los años 2000, se fue por un camino mucho más oscuro", manifestó Dino, de la banda Degaruda (Dino Tarasin, entrevista 5 de abril de 2014). Una vez que las disqueras más importantes se dieron cuenta del impacto de la música independiente sobre la juventud tailandesa, y el mercado que significaba, empezaron a firmar contratos con bandas y a comercializarlas, volviendo a saturar con ellas los medios. Sin embargo, el espíritu DiY seguía anclado entre los jóvenes locales y, una vez más, la subcultura del rock'n'roll conservó su estatuto underground, aunque explotó en una miríada de estilos musicales y escenarios.

\section{Punk, Hardcore y el renacimiento del metal Punk}

A finales de los 90 y principios de la siguiente década, la escena independiente en Bangkok había sido casi absorbida por la maquinaria dominante de los medios de comunicación; no obstante, fueron abiertos nuevos espacios musicales para contrarrestar esa hegemonía cultural y musical. Siguiendo el movimiento DiY, la música Punk apareció en Tailandia en 1997 en Chiang Mai y en Hat Yai. En esa primera ciudad, surgió incluso unos años antes de que se moviera a Bangkok en el año 2000 en busca de una mayor audiencia. 
Chaos City era el epicentro de la actividad Punk en Chiang Mai. Era una suerte de casa, ocupada ilegalmente, ubicada en Moonmuang Road Soi 9, en donde la gente vivía en los pisos superiores, organizaban conciertos y tenían un bar abajo. "Era como un circo, tenían columpios y trampolines, un circo alcoholizado en el que la gente siempre acababa herida al querer utilizar los columpios cuando habían bebido demasiado" (Marc Savlov, entrevista 1ero de abril de 2014). Chaos City había sido abierto y estaba administrado por Sophie, una joven estadounidense que se había involucrado con el movimiento punk americano desde su juventud temprana, y su novio tailandés Kae.

Según Marc Savlov, periodista estadounidense del Austin Chronicle que investiga a los Punks en Tailandia, en un principio, ese lugar y sus participantes fueron "muy influenciados por The Casualties —una banda Punk de Estados Unidos-y ambos se inspiraron en ellos en la forma de vestir y actuar" (Marc Savlov, entrevista 1ero de abril de 2014). Pero, al contrario de lo que ocurría en los movimientos del Punk en el occidente, el movimiento Punk tailandés nunca fue abiertamente anti-establishment ni asumió compromisos políticos claros. Una vez que el movimiento devino demasiado fuerte para quedarse en Chiang Mai, las bandas Punk migraron a Bangkok buscando acceder a nuevos espacios para tocar. Sin embargo, conflictos internos entre distintas facciones llevaron a que se escindieran. Se separaron los Punks Mohawk, caracterizados por sus crestas multicolores, que pasaban la mayor parte de su tiempo cerca del mercado de pulgas de fines de semana en Chatuchak, también los Punks Hardcore que se habían instalado en distintos bares en la ciudad, incluyendo áreas como las de Town in Town o cerca del Monumento a la Victoria — Victory Monument. 
Foto 2. Mohawk Punk durante un concierto en el Rusty Bar, en Town in Town, Bangkok.

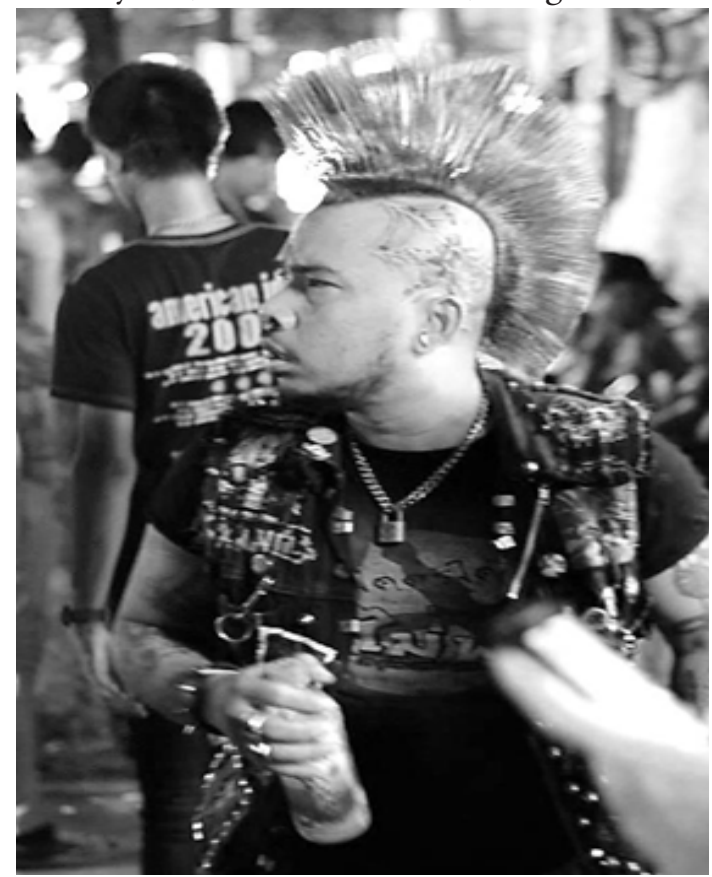

\section{Punk Hardcore y Straightedge Hardcore}

Una vez en Bangkok, y después de la separación de las distintas corrientes, los jóvenes tailandeses que preferían la música Hardcore empezaron a frecuentar lugares como el Inmortal Bar cuando éste todavía estaba ubicado en Khaosan Road. Los fanáticos de este estilo musical se llamaban THHC, Tailandia Hardcore, y eran célebres por su ingesta de grandes cantidades de alcohol durante los conciertos locos que escenificaban. Como lo explicó Gap, el propietario de Holding On Records, el Hardcore surgió cuando un joven estadounidense, llamado Christopher Luppi, llegó a Tailandia. Luppi estaba viajando por Asia del Sudeste y traía casetes y CD de bandas Hardcore de Estados Unidos como Madball y Agnostic Front. En esa época, Immortal Bar permitía a la gente tocar la música que llevaban en sus viajes y fue así como el Hardcore ingresó a la escena musical. Después de una temporada, 
Christopher continuó su viaje pero dejó copia de su música a los jóvenes tailandeses con quienes había convivido durante su viaje por Bangkok. Christopher regresó a Tailandia después de algunos meses y decidió establecerse en la ciudad por un tiempo indefinido. Fundó la disquera Elephant Eyes Records que introdujo y distribuyó CD de bandas extranjeras de Hardcore en Tailandia. Con la ayuda de un estudiante universitario llamado Yos, Christopher empezó a organizar conciertos y contratar bandas extranjeras para que tocaran en Bangkok (Nutpongtorn 'Gap' Sittiboon, entrevista 22 de mayo de 2014). Paulatinamente, ambos crearon su propio ámbito Punk Hardcore en la ciudad. Cuando Chris dejó el país, la marca desapareció a la par que luchas internas aparecían entre diversas corrientes.

"Expulsados" del Immortal Bar, una parte del grupo original del THHC estableció contactos con mochileros que se adherían al movimiento Straightedge, nacido en los 80 en Washington DC bajo el impulso de la banda Minor Threat. Este movimiento condenaba el uso de drogas, de alcohol y la actividad sexual como formas de recreación, argumentando que inhibían las posibilidades de rebeldía contra el establishment. Esas perspectivas contrastaban fuertemente con la fama del THHC, que congregaba bebedores empedernidos, sexualmente desenfrenados, así ambas corrientes se separaron. Surgieron los SXT o Grupo Straightedge Tailandés, y el HDB o equipo Hardcore Drinking Bangkok, el cual en 2014 cambió su nombre por el de Fraternidad Hardcore Drinking — Hardcore Drinking Brotherhood, por sus siglas en inglés-. Pese a sus divergencias sobre el consumo de drogas y alcohol, ambas corrientes cooperan y co-existen, porque la escena Punk es demasiado reducida para partirse en dos. Como lo señaló Gap, ambos grupos "tienen distintas opiniones sobre alcohol, drogas y sexo pero escuchamos la misma música” (Nutpongtorn 'Gap' Sittiboon, entrevista 22 de mayo de 2014). La escena Hardcore, de hecho, pese a sus disensiones internas, está bien organizada: tiene su propia marca de discos, que produce artistas locales y distribuye $\mathrm{CD}$ de extranjeros, organizan conciertos y los músicos locales tienen conexiones internacionales con sus pares de otros países de Asia, donde van eventualmente a promocionarse. El Immortal Bar cambió de 
ubicación debido al encarecimiento de las rentas en el barrio de la calle Khaosan, que ha devenido en un lugar de concentración internacional de mochileros y se ha reinstalado cerca del Victory Monument, donde mantiene sus actividades, siendo uno de los epicentros de la música del metal en Bangkok.

Foto 3: El periodista Marc Savlov (izquierda); Víctor, de la banda Hardcore The State of Society (TSOS, centro), con la banda de Oi! Punk The Botox, en el restaurante Fatty's después de un concierto

[foto proporcionada por Dave Crimaldi].

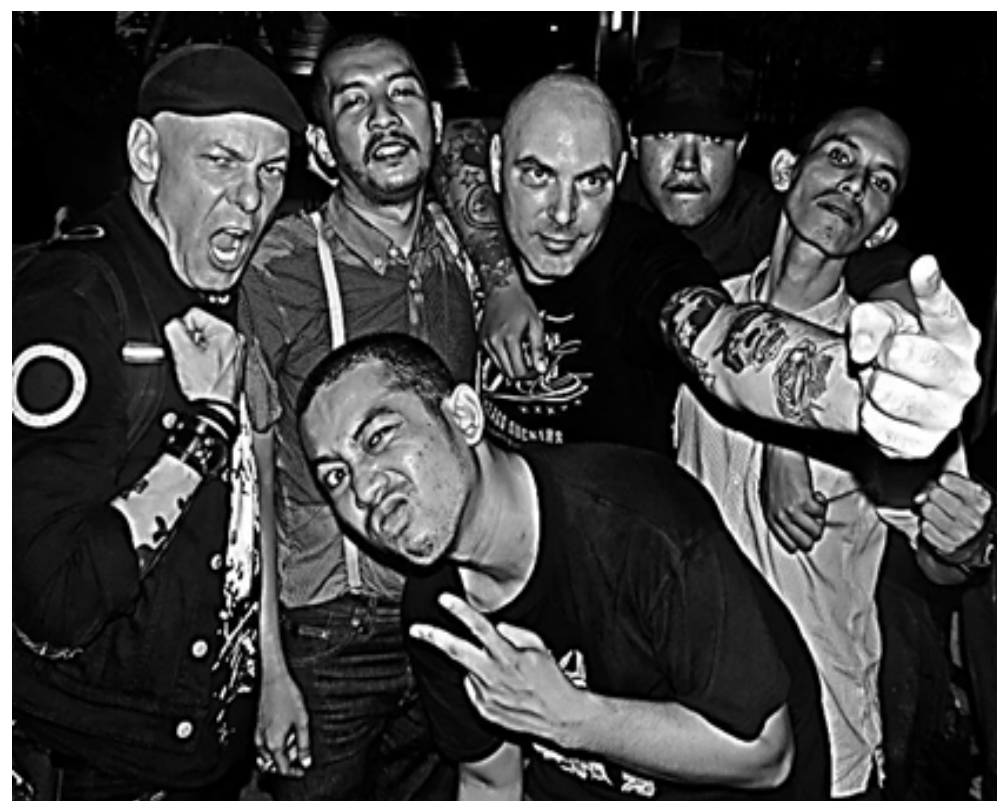

\section{El renacimiento del Metal}

Como vimos más arriba, los 80 fueron la década del Metal Trash en Tailandia. El impacto que tuvo a escala local fue enorme, no sólo influyó en la constitución y expansión de una subcultura del rock'n'roll como un todo, sino que además permitió a otras corrientes de la escena del Metal desarrollarse: como el Death Metal y el Doom Metal. Pero fue hasta la segunda mitad de los 90 y principios del año 2000 cuando 
una segunda ola de Metal se abatió sobre Bangkok, bajo la influencia de la banda Plahn, que logró ser un referente en el escenario local y realizó giras en toda Asia del Sureste. Su cantante principal, Fah, es el propietario del Immortal Bar, y explicó así la importancia del Metal en la subcultura del rock'n'roll en Bangkok:

El Metal fue una revelación para muchos de nosotros. Nunca habíamos oído algo así y una vez que lo hicimos, no podíamos más que burlarnos de la música que oíamos en la radio. Era vacía, aburrida y repetitiva. Después de que las primeras bandas se hicieran famosas en los 80 , descubrimos que la escena había evolucionado rápidamente y estaba dominada por bandas como Metallica, Pantera y Slayer. Yo quería tocar y oírme como ellos: lo que se hacía en los 80 aparecía de repente muy lento (Fah, entrevista 10 de abril de 2014).

Después del éxito de su banda Plahn, Fah abrió el Immortal Bar en el año 2000 como un lugar donde los amantes del Metal y del rock'n'roll podían reunirse para escuchar música, platicar y beber cervezas heladas. Fah utilizó su influencia en ese ambiente para organizar conciertos con regularidad; el Immortal Bar se transformó rápidamente en una parada obligada para quienes se interesaban en la música rock'n'roll independiente. Su ubicación estratégica en la calle Khaosan permitió a los jóvenes tailandeses encontrarse con mochileros extranjeros y oír la música de sus países. Asi, los escandinavos trajeron Death y Doom Metal a los tailandeses, que adoptaron con delicias esos sonidos todavía más distorsionados que los que solían oír. La banda Plahn se deshizo, pero Fah formó otra que llegó a ser todavía más exitosa, Carnivora. Después de tantos años de tocar Metal, Fah explicó que para él, la música es una forma de conjuntar a la gente. Para lograrlo, decidió cantar en inglés en lugar de hacerlo en tailandés:

Cuando empezamos, evidentemente, cantamos covers en inglés, pero cuando escribimos nuestras propias canciones, 
muchas bandas deciden cantar en tailandés. Para mí, el tailandés no puede realmente ser utilizado para expresarme, entonces, el inglés era la única opción viable. Si canto en tailandés, nadie fuera del país va a poder entender mi música, y quiero que mi música sea universal. Originalmente, el metal llegó de América a Tailandia pero ahora se está generando aquí también, y podemos dialogar desde aquí con América si cantamos en inglés (Fah, entrevista, 10 de abril de 2014).

El éxito del Metal en general en Bangkok, y de Carnivora en particular, indican que ahora la subcultura del rock'n'roll y la escena del Metal han evolucionado y se han adaptado a las necesidades musicales de la juventud tailandesa. Aunque las escenas musicales vinculadas con las subculturas empezaron a ser absorbidas por los medios, debido a su comercialización potencial, las subculturas lograron re-inventarse y desarrollar nuevos ámbitos y sonidos.

Foto 4. Carnivora en concierto en el Immortal Bar, Bangkok.

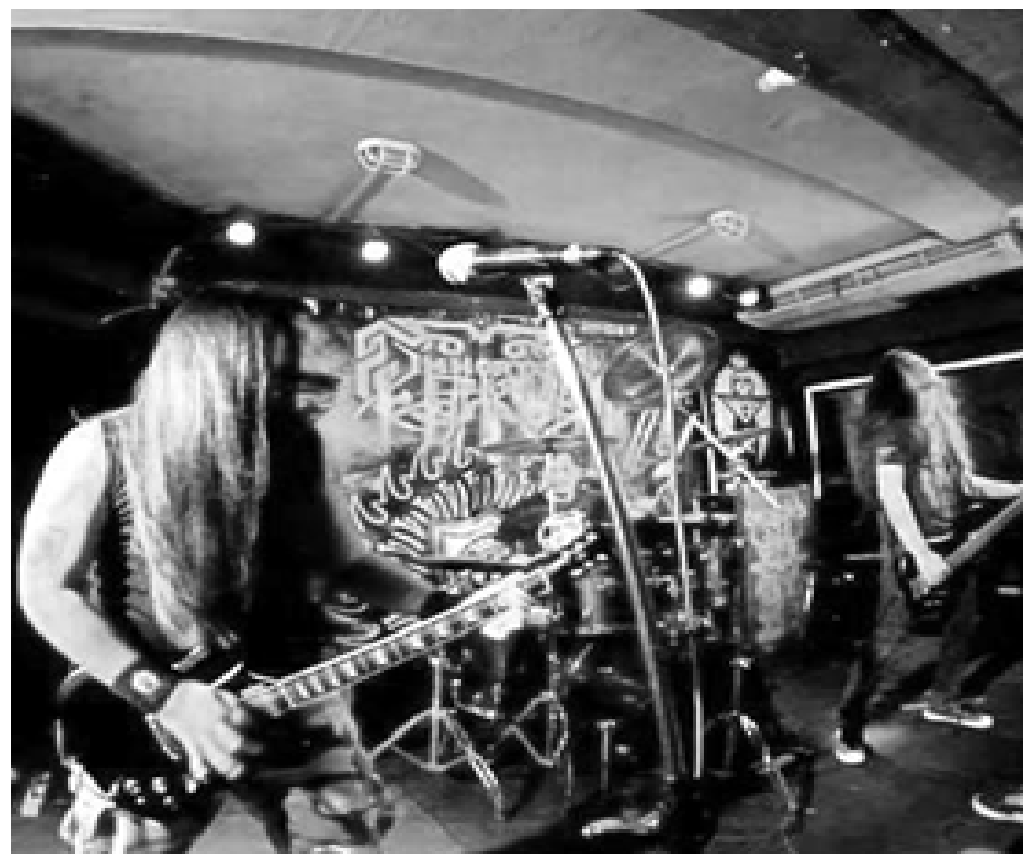


Todavía nos falta explorar quiénes integran esa juventud tailandesa, misma que participa en la música rock underground en Bangkok, un tópico al que dedicaremos el resto de este artículo.

\section{2. ${ }^{\mathrm{a}}$ Parte}

\section{Descubriendo y volviéndose parte del ámbito del rock under- ground en Bangkok}

La siguiente sección detalla los primeros contactos con la subcultura del rock'n'roll en sentido amplio antes de participar directamente en esa escena. Las experiencias revelan prácticas de ensayo y error que van conformando los gustos musicales y referencias de los futuros participantes de la escena. Es importante cuidarse de denigrar la participación temprana so pretexto de trivialidad o inautenticidad.

Tres factores son cruciales para explicar el proceso de sensibilización e ingreso a la subcultura del rock en Bangkok: la exposición a los medios de comunicación, la introducción vía los pares o la familia, y la universidad. La mayoría de los informantes recuerda que su acercamiento al rock'n'roll se produjo a finales de la adolescencia, principalmente cuando estaban estudiando en la universidad. Eso es un rasgo original en relación con lo que muestran otros estudios que indican que el interés por otras subculturas musicales se produjo a principios de la adolescencia (Andes, 1998; Leblanc, 1999). No obstante, los entrevistados habían tenido anteriormente contactos con la música siendo niños, aun cuando esa música nada tuviese que ver con el rock'n'roll. Como en otras muchas partes del mundo, las familias de clase media en Tailandia consideran que es importante que los niños aprendan a tocar algún instrumento. De hecho, en Tailandia ser profesor de piano es altamente valorado socialmente, la Reina fue educada para ser pianista de concierto y es, en consecuencia, muy común que las familias paguen cursos de música clásica a sus hijos.

Dino, el guitarista de la banda Degaruda, anteriormente de From The Makers of Casablanca y The Eastbound Downers, nos comentó: 
Siempre hubo música en mi vida, nuestros padres siempre tocaban algo y eso es algo que querían todas las familias tailandesas. Aprendí a tocar piano cuando era nińo y poco a poco transité a la guitarra y al rock'n'roll cuando era adolescente (Dino Tarasin, entrevista 5 de abril de 2014).

Foto 5. Los hermanos Tarasin, Dino (al frente) y Top, en concierto durante el estreno del CD de su banda, Degaruda, en el Harmonica.

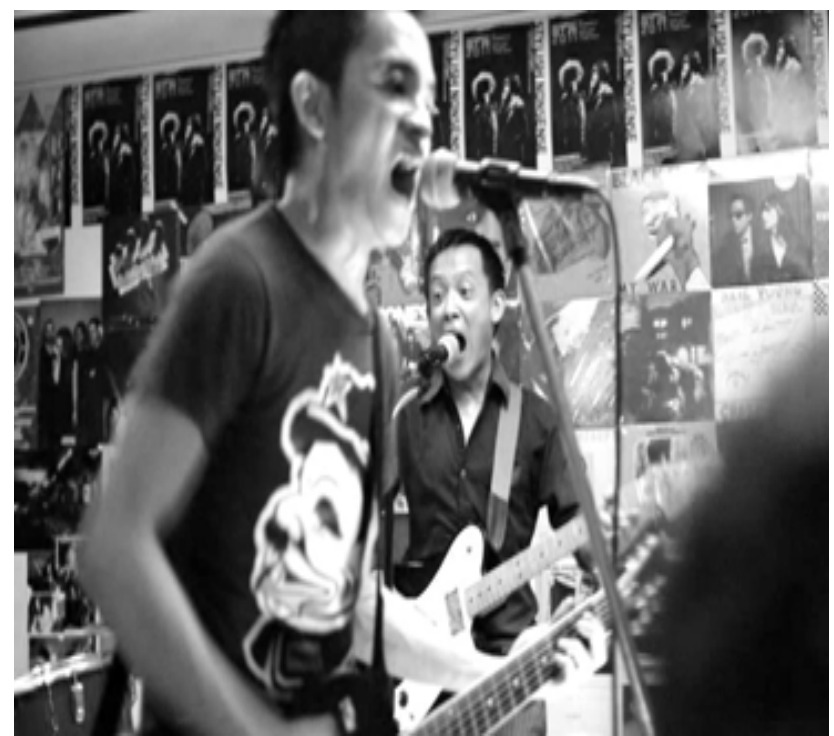

También Yong, el guitarrista de la banda de rock psicodélico Chladni Chandi, menciona la influencia de los padres deseosos de que sus hijos sepan tocar un instrumento:

Fundamentalmente, soy un violinista con una formación musical clásica. Me enseñaron desde muy chico, mis padres me inscribieron en clases privadas a las que iba dos veces por semana. Fue sólo mucho más tarde cuando descubrí el rock (Chalawit 'Yong' Saowapakpongchai, entrevista 12 de abril de 2014). 
Foto 6. Chalawit 'Yong' Saowapakpongchai de Chladni Chandi [Foto de Dave Crimaldi].

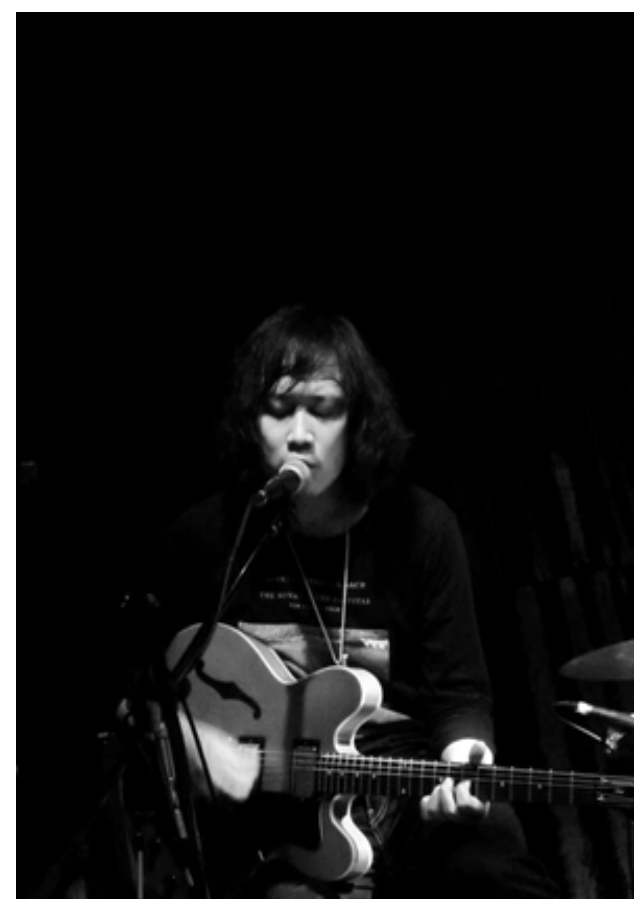

La experiencia musical de parte de los rockeros en Bangkok inició a una edad muy temprana por el interés de los padres en darles una formación musical clásica. Muy pocas veces tuvieron la posibilidad de elegir su instrumento $y$, muchas veces, la música no era más que una actividad extra-curricular entre otras. No obstante, una vez que descubrieron el rock, trocaron su instrumento inicial por la guitarra, el bajo o la batería. La forma como se produjo ese descubrimiento cambió según los participantes, aunque comparten algunas experiencias como haberse enganchado al rock y haberse dedicado activamente a explorar las vertientes del género.

Durante la entrevista, Wannarit 'Pok' Pongprayoon, uno de los dos miembros de Stylish Nonsense, subrayó que escuchaba música tailandesa todo el día en el radio pero que fue sólo hasta que llegó a la Universidad cuando empezó a escuchar música extranjera como el jazz, 
el blues y el rock. Somsiri 'June' Sangkaew, de Bear-Garden, dice que se sentía desencantada con la música tailandesa que transmitían los medios, por lo que empezó a ver y escuchar emisiones de MTV en las noches y, buscando algo distinto, encontró el rock. Aunque le pareció demasiado violento para ella, se percató que existían muchos más géneros musicales que los accesibles en los medios locales y empezó a indagar en la cartelera musical de la ciudad (Somsiri 'June' Sangkaew, entrevista, marzo de 2014). Pero, en una trayectoria muy similar a la de Pok, fue en sus años universitarios cuando encontró realmente un grupo de personas con sus mismas inquietudes, el estar buscando hacer su propia música sin preocuparse de lo que la sociedad opinara de ellos.

\section{Universidad: el lugar donde los aspirantes a músicos se en- cuentran y se forman}

La mayoría de los informantes evocan charlas con amigos o hermanos, así como con otros familiares, como una segunda clave en su descubrimiento del rock. De su interés inicial por el metal, June saltó al Pop Británico y a bandas locales como Modern Dog y Krup, una vez que empezó a ir a la universidad. Como estudiante de Bellas Artes en la Universidad Kasetsart, encontró mucha gente adscrita a los departamentos de estudios musicales y, poco a poco, se sintió atraída por distintos estilos musicales que sus compañeros tocaban o experimentaban (Somsiri 'June' Sangkaew, entrevista 6 de marzo de 2014). Ese esquema es recurrente: casi todos los entrevistados empezaron en forma seria sólo después de matricularse en las universidades.

Algunos estaban inscritos en departamentos de estudios musicales y otros cursaban carreras de tipo creativo. Pok se matriculó en el Departamento de estudios musicales de Kasetsart University y fue allí donde encontró a músicos extranjeros. Descubrió así el rock’n'roll cuando Krub, la banda local que encabezaba la segunda ola del rock independiente, llegó a hacer un espectáculo en vivo en el campus.

Yong, de la banda Chladni Chandi, tuvo una historia parecida, pues participó en una primera banda durante sus estudios universitarios: 
Cuando era chico, mi familia acostumbraba tocar música vieja, los Beatles y rock de los 60. En ese momento, ni me interesaba ese tipo de música, pero, conforme fui creciendo, me descubrí una pasión por el rock: empecé a tocar cuando estaba en prepa. [En la universidad] fui a estudiar violín pero, en el Departamento, encontré a mucha gente tocando otros instrumentos y es así como descubrí propiamente dicho el bajo y la guitarra. Participé en mi primera banda en aquella época y empece a tocar el bajo eléctrico porque no podía todavía tocar la guitarra. Un amigo mío me enseñó a tocar y fue así como empecé con la música rock (Chalawit 'Yong' Saowapakpongchai, entrevista, 12 de abril de 12).

Foto 7: Yong (izquierda) tocando con Chladni Chandi en Angel City Diner, 26 de febrero de 2014.

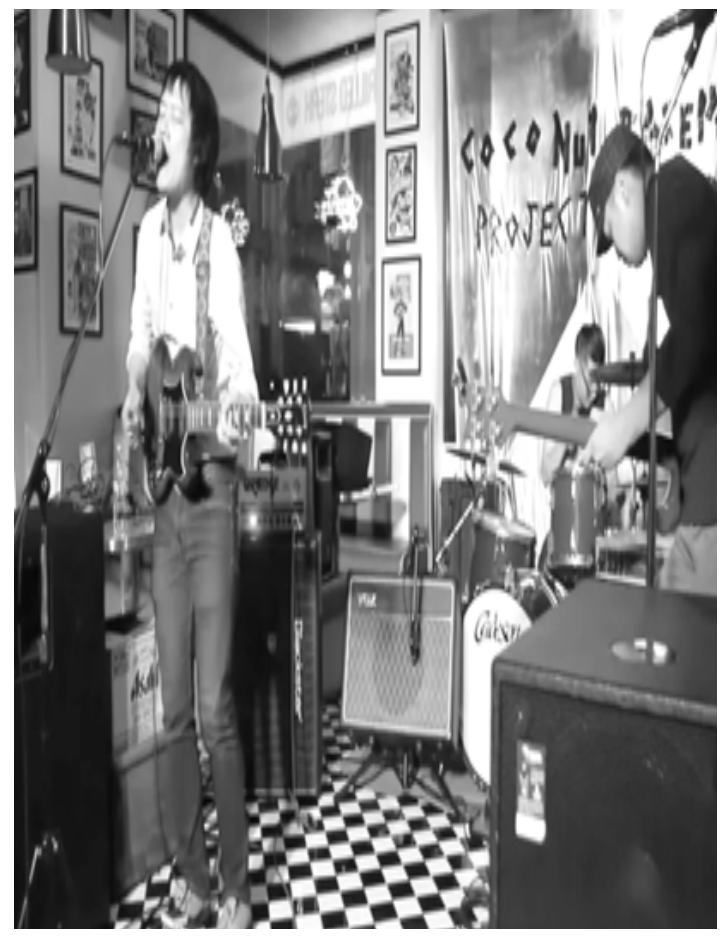


En este contexto, podemos notar el papel importante desempeñado tanto por la familia como por las relaciones de pares para explicar el interés de Yong en el rock. Pasó una fase de descubrimiento casi sin darse cuenta debido al interés de sus padres en el rock de los 70 y a la escucha permanente de música en su casa. Aunque, en ese momento, el rock le parecía aburrido a Yong porque lo asociaba con los gustos anticuados de sus padres, le encontró interés durante la prepa, pero fue hasta que ingresó a la Universidad Srinakharinwirot cuando decidió probarse como músico. En ese punto, pasa a la segunda fase de un proceso de ingreso en una subcultura, la de la exploración. Como estaba cursando violín, utilizó la facultad de música como plataforma para establecer una red de pares que compartían sus mismos intereses en la música rock. A través de una de sus contactos, aprendió a tocar guitarra y bajo y formó una banda, Van de Aire, y Degaruda transitó por un camino parecido:

Empecé a tocar guitarra pero era realmente malo hasta que fui a la escuela para que me enseñaran. Casualmente, en la prepa, empecé a tocar batería sólo porque era chistoso. Cuando empecé estudios superiores, quería tocar en una banda porque, en aquel periodo, creía que no se necesitaba ser muy bueno en una banda, pero cuando ingresé a la primera me di cuenta de que era cosa seria. Me dije: Pues, tengo que mejorar y prestarle atención a cómo toco (Van Lakarnchua, entrevista, 5 de abril de 2014).

Otro informante que siguió el mismo esquema de descubrimiento es Nop, de Govinda Bhasya, quien se tituló en la Universidad de Chandrakasem con especialidad en el bajo y descubrió la cítara durante su tercer año de su carrera.

En la Universidad, estaba inscrito en el Departamento de música y solía tocar bajo. Durante mi tercer año, mezclé música de la India y tecnología como la música electrónica, lo que finalmente fue mi proyecto de tesis, y dio lugar al 
Proyecto musical actual de Govinda Bhasya (Noparuj 'Nop' Satjawan, entrevista, 12 de abril de 2014).

Foto 8: Noparuj 'Nop' Satjawan, tocando en el marco de Govindha Bhasya en Stone Free 3, 2014.

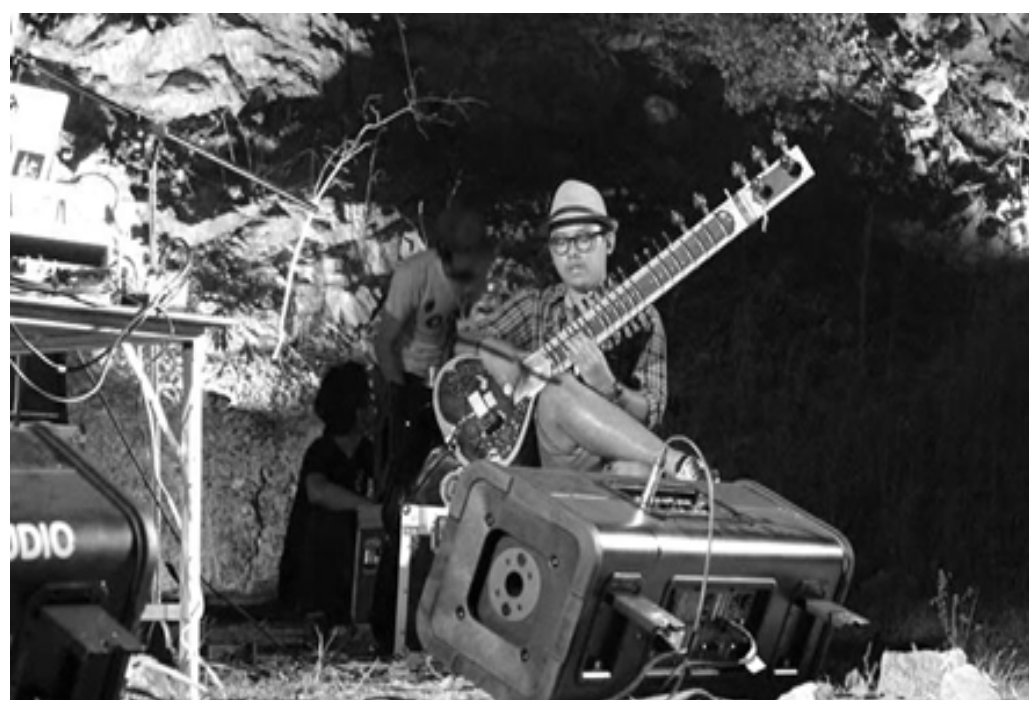

Somsiri 'June' Sangkaew de Bear Garden y Wannarit 'Pok' Pongprayoon, de Stylish Nonsense, se encontraron en la Universidad Kasetsart. Su amistad e interés común por la música rock'n'roll sustentaron una colaboración que les permitió crear lo que con el tiempo se volvería la disquera independiente más importante de todo el país: Panda Records. Así, la universidad desempeñó un rol de pivote entre la juventud tailandesa en su exploración de la cultura del rock. Es en esas instituciones de donde surgieron muchas bandas de rock'n'roll tailandés. Las universidades permitieron a los jóvenes refinar sus gustos por ese tipo de música mediante un proceso de ensayo y error. Desde el movimiento del puea chiwit en los 70 hasta el Punk, el Metal y la escena rock independiente de hoy, las universidades en Bangkok contribuyeron a afianzar la autopercepción de los jóvenes tailandeses vía su involucramiento en ámbitos musicales. Las interacciones entre pares no son sin embargo el único medio de los jóvenes tailandeses de 
clase media para que se adentren en el rock; también intervienen allí familia y amigos en la definición de los gustos musicales.

\section{Consideraciones finales}

Las personas cercanas son importantes en el proceso de ingreso a la subcultura, sea porque dan a conocer grupos particulares sea porque ayudan a los informantes a definir sus preferencias musicales. La influencia tradicional de los padres, durante esa etapa, ha sido recordada como restrictiva en la medida en que dificultó el ingreso y la participación de los jóvenes en la subcultura del rock. Lo ilustra el ejemplo descrito por Leblanc (1999) al detallar los resquemores de los padres ante la subcultura del Punk Rock. Nuestra conclusión es, sin embargo, algo diferente: los padres, si bien tienen distintas aspiraciones musicales, orillaron a sus hijos a aprender a tocar un instrumento. Los entrevistados reconocieron de hecho la importancia de haber oído música en casa en relación con la adquisición de un gusto por ella y después por el rock'n'roll. Bandas como Carpenters, Beatles, Jimi Hendrix, Deep Purple, Joe Cocker y Janis Joplin, entre muchas otros, fueron citadas como grupos del interés de sus padres. Esa situación preparó su descubrimiento ulterior de la subcultura rock que les sirvió para afianzar su nicho y su gusto personal. Como lo señalaron Yong, Van y Dino, gravitaron paulatinamente hacia una música de su interés sin dejar de apreciar la que oyeron con sus padres. Fue al empezar a tocar en bandas cuando su estatuto como miembros periféricos o semiperiféricos de una subcultura se trasnmutó en uno de miembros de pleno derecho.

Como señalamos en este artículo, los jóvenes tailandeses lograron asentar y difundir una identidad propia sólo cuando se consolidó a finales de los 70 y principios de los 80 una clase media económicamente próspera. Esa identidad originalmente fundamentada en la música rock extranjera evolucionó muy rápidamente hasta que permitió producir una genuina. En menos de diez años, lo que inició el género del Metal se diversificó en rock independiente, Punk y otros géneros, cada uno con sus propios espacios. Esos espacios aparecieron, más o menos simultáneamente, en Bangkok mismo o bien se movieron del 
exterior a la capital. Cuando iniciaron la promoción de la música en vivo, no existía una infraestructura para su reproducción cotidiana y su consumo. Sin embargo, los escenarios permitieron dar a conocer los sentimientos y pensamientos de los músicos. Es necesario aprender la historia de este tipo de música para poder comprender y estudiar de manera adecuada los textos y contextos del rock underground tailandés. Como parte de una investigación más amplia se llevará a cabo un estudio comparativo entre rock en Tailandia y rock en México, esperando poder así encontrar paralelismos y diferencias con respecto a los jóvenes que se dedican a estos tipos de música y las sociedades en las que se desarrollan.

\section{Bibliografía citada}

Andes, L., 1998, "Growing Up Punk: Meaning and Commitment Careers in a Contemporary Youth Subculture”, en J. Epstein (editor), Youth Culture: Identity in a Postmodern World, Blackwell, Oxford.

Apanich, M., 2002, "Do it yourself music": its role as a subculture in Thai Popular Music, Master Degree Thesis in Thai Studies, Chulalongkorn University, Bangkok.

Frykman, J., \& Lofgren, O., 1987, Culture Builders: A Historical Anthropology of Middle-class Life, Rutgers University Press, New Brunswick, NJ.

Kasian, T., 2001, "The postmodernization of Thainess", en S. Yao (editor), House of Glass: Culture, Modernity and the State in Southeast Asia, ISEAS, Singapore, pp. 150-172.

Leblanc, L., 1999, Pretty in Punk: Girls' Gender Resistance in a Boys' Subculture, Rutgers University Press, Brunswick, New Jersey.

Myers-Moro, P., 1986, "Songs of Life: Leftist Thai Popular Music in the 1970s”, Journal of Popular Culture, núm. 20, pp. 93-114.

Ockey, J., 2004, Making Democracy: Leadership, Class, Gender, and Political Participation in Thailand, University of Hawaii Press.

Thompson, E. P., 1966, The Making of the English Working Class, Vintage Books. 
Wong, D., 1989, "Thai Cassettes and Their Covers: Two Case Studies”, Asian Music, núm. 21, pp. 78-104.

\section{Lista de fotografías}

Foto 1. Wannarit 'Pok' Pongprayoon, tocando con Plastic Section en Harmonica.

Foto 2. Punk Mohawk durante un concierto en el Rusty bar, en Town in Town, Bangkok.

Foto 3. El periodista Marc Savlov (izquierda), Víctor, de la banda Hardcore The State of Society (TSOS, centro) con la banda de Oi! Punk The Botox, en el restaurante Fatty's después de un concierto [foto proporcionada por Dave Crimaldi].

Foto 4. Carnivora en concierto en el Immortal Bar, Bangkok.

Foto 5. Los hermanos Tarasin, Dino (al frente) y Top, en concierto durante el estreno del CD de su banda, Degaruda, en Harmonica.

Foto 6. Chalawit 'Yong' Saowapakpongchai de Chladni Chandi [Foto de Dave Crimaldi].

Foto 7. Yong (izquierda) tocando con Chladni Chandi at Angel City Diner, 26 de febrero de 2014.

Foto 8. Noparuj 'Nop' Satjawan, tocando en el marco de Govindha Bhasya en Stone Free 3, 2014. 